\title{
STRUKTUR MIKRO DAN SIFAT MEKANIS ALUMINIUM PADUAN SERI 6063 HASIL COR DARI CETAKAN LOGAM, PASIR RESIN FURAN DAN PASIR KOMOSSA
}

\author{
Chris Marvin A., Eddy S. Siradj dan Sobron Y.L. \\ Jurusan Teknik Mesin, Fakultas Teknik Universitas Tarumanagara
}

\begin{abstract}
Material developments in Indonesia is already very advanced rapidly certainly need high level of violence but has a mass of light. Aluminum should be developed because it possesses a lightweight and available in the land of our country that is rich in agricultural products. As an alternative to strengthen aluminum alloy that is with Si and $\mathrm{Mg}$, as well as the rapid cooling process when smelting. This study was conducted to observe the microstructure and mechanical properties of the raw material of aluminum alloy series 6063. Tests conducted with metal mold, furan resin sand mold, commossa sand mold, the cooling rate of each mold will affect the hardness of the material which can be seen microstructure with microstructural observations. The survey results revealed that the aluminum with a metal mold casting has a hardness of $54 \mathrm{HRB}$, furan resin sand has a hardness of $40 \mathrm{HRB}$, sand commossa has a hardness of 33 HRB. Metal mold has a shock force of 0,316 J/mm2, particularly a furan resin sand shock force of 0,265 $\mathrm{J} / \mathrm{mm} 2$, commossa sand has a shock force of $0.206 \mathrm{~J} / \mathrm{mm} 2$. Metal mold has a high hardness compared with furan resin sand rated second, while the sand was rated commossa end but increasingly harsh mean tenacity of a material value will increase. According to the test micro structure, the aluminum is brittle, the distance or the distribution of grain will be a meeting or a lot.
\end{abstract}

Keywords: aluminum alloy, the rate of cooling, lightweight and durable, grain distribution.

\begin{abstract}
Abstrak: Perkembangan material di Indonesia sudah sangat maju pesat tentunya membutuhkan tingkat kekerasan yang tinggi tetapi memiliki massa yang ringan. Aluminium perlu dikembangkan karena memiliki sifat yang ringan dan tersedia di tanah Negara kita yang kaya akan hasil bumi. Sebagai alternatif untuk menguatkan aluminium yaitu dengan paduan Si dan Mg, serta proses pendinginan yang cepat saat peleburan. Penelitian ini dilakukan untuk mengamati struktur mikro dan sifat mekanis bahan baku aluminium paduan seri 6063. Pengujian dilakukan dengan metal mold, pasir resin furan mold, commossa sand mold, laju pendinginan dari setiap mold akan mempengaruhi dari nilai kekerasan material tersebut yang dapat dilihat struktur mikro dengan pengamatan mikrostruktur. Dari hasil penelitian diketahui bahwa aluminium dengan pengecoran cetakan logam memiliki kekerasan $54 \mathrm{HRB}$, pasir resin furan memiliki kekerasan 40 HRB, pasir komossa memiliki kekerasan 33 HRB. Metal mold memiliki kekuatan kejut sebesar $0,316 \mathrm{~J} / \mathrm{mm}^{2}$, pasir resin furan meiliki kekuatan kejut 0,265 J/mm², pasir kommossa memiliki kekuatan kejut sebesar 0,206 J/mm². Cetakan logam memiliki kekerasan yang tinggi dibandingkan dengan pasir resin furan diperingkat kedua, sedangkan pasir komossa berada diperingkat akhir tetapi semakin tidak keras berarti nilai keuletan suatu material akan semakin bertambah. Menurut pengujian struktur mikro, semakin aluminium tersebut bersifat getas maka jarak atau persebaran butir akan semakin rapat atau banyak.
\end{abstract}

Kata Kunci: aluminium paduan, laju pendinginan, ringan dan kuat, persebaran butir.

\section{PENDAHULUAN}

Dalam setiap benda yang digunakan dalam kehidupan sehari-hari terbuat dari berbagai macam material. Material tersebut dapat berupa bahan logam dan nonlogam seperti besi, alumunium, polimer, karet, dan lain-lain. Hal ini menyebabkan berkembangnya sifat pada material-material yang digunakan untuk berbagai pekerjaan dan penggunaan. Pada saat ini banyak dilakukan penelitian dari proses peleburan dan cetakan. Peleburan aluminium menggunakan bahan bakar LPG dengan polusi udara yang sedikit dan berbagai cetakan dengan keunggulan dari masing-masing cetakan.

Akhir-akhir ini para peneliti berusaha menghasilkan aluminium dengan meningkatkan sifat mekanis dan biaya produksi yang rendah mulai dari proses peleburan dan cetakan yang lebih baik dari peneliti sebelumnya. Pada proses peleburan, tingkat suhu dapat mempengaruhi hasil sehingga tidak dianjurkan melebihi jauh di titik lebur, cetakan juga ada berbagai macam jenis dengan keunggulan seperti biaya yang murah dan cetakan yang memiliki sifat melepas kalor cepat untuk mempercepat pembekuan bahan baku. Penelitian ini dilakukan untuk mengetahui pengaruh sifat cetakan terhadap hasil sifat mekanis dan struktur mikro dari bahan baku. 


\section{METODE PENELITIAN}

Metode penelitian dibuat untuk menyusun langkah-langkah yang akan dilakukan dalam melakukan penelitian sehingga penelitian berjalan secara sistematis dan terarah. Adapun langkahlangkah yang dilakukan dapat dilihat dalam Gambar 1. Setelah pengujian dilakukan, data-data yang didapat akan dianalisa lebih lanjut. Tahap terakhir adalah kesimpulan dan saran.

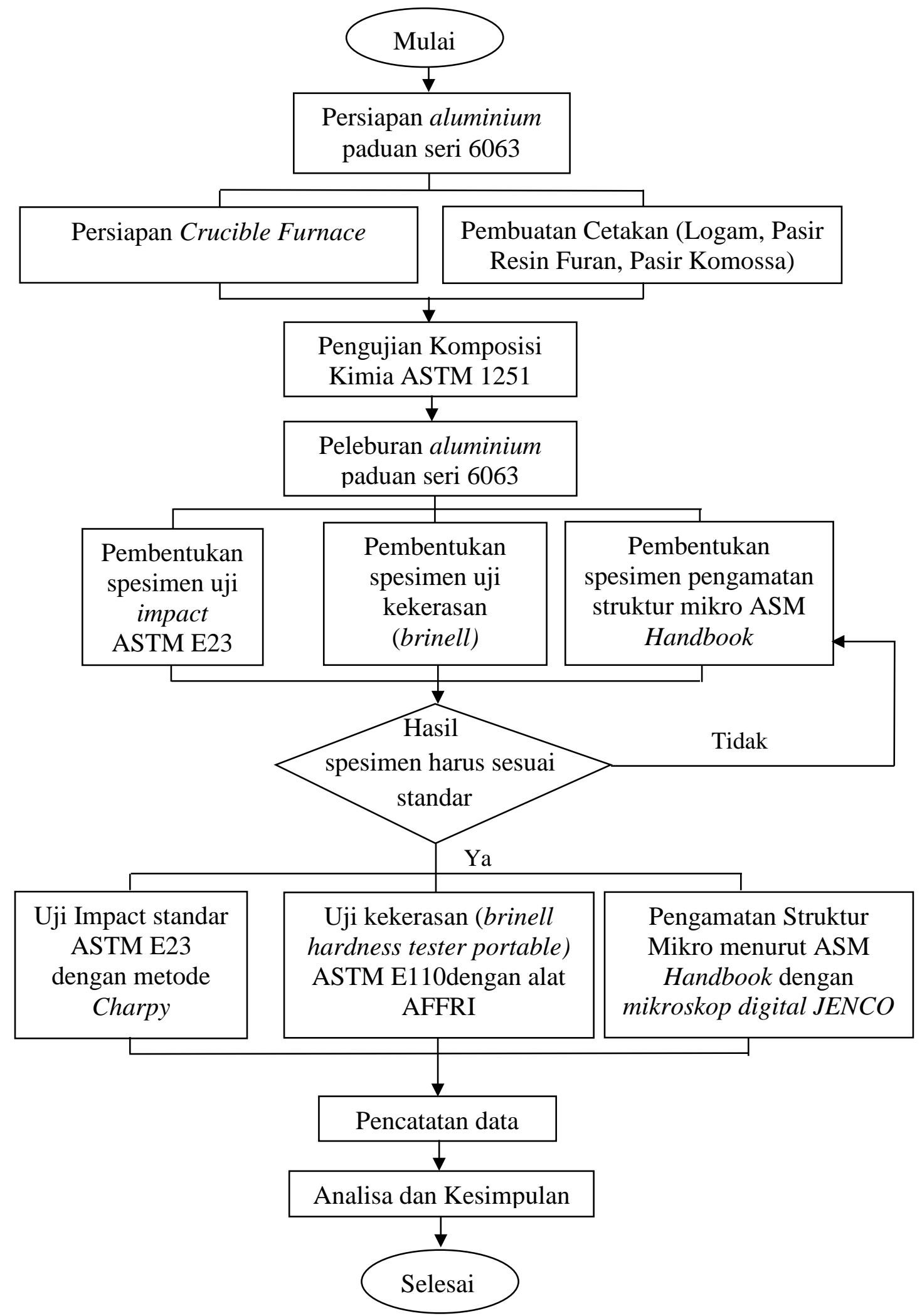

Gambar 1. Diagram alir metode penelitian 
Prosedur penelitian meliputi beberapa tahap, yaitu:

a. Persiapan Aluminium paduan seri 6063

Bahan baku yang digunakan adalah Aluminium paduan seri 6063 berbentuk velg motor.

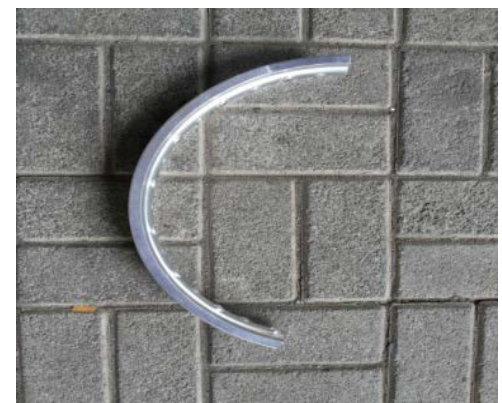

Gambar 2. Bahan baku Aluminium paduan seri 6063

\section{b. Pembuatan cetakan logam, pasir resin furan, dan pasir komossa}

Cetakan yang digunakan ada tiga yaitu cetakan logam dengan bahan baja ST41, cetakan pasir resin furan, dan cetakan pasir komossa.
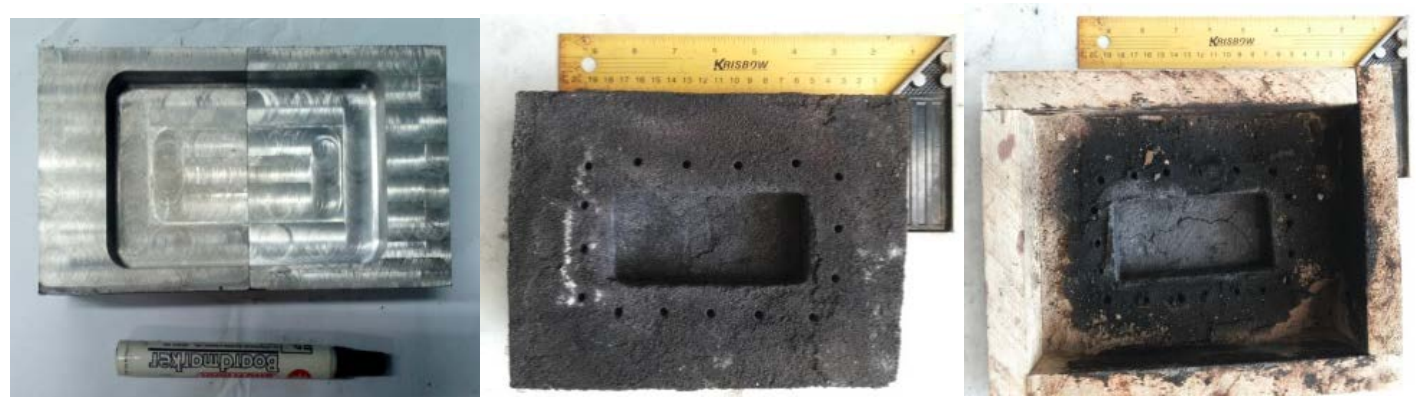

Gambar 3. Cetakan logam, pasir resin furan, dan pasir komossa

c. Peleburan Aluminium paduan seri 6063

Peleburan menggunakan tungku dengan bahan bakar LPG.

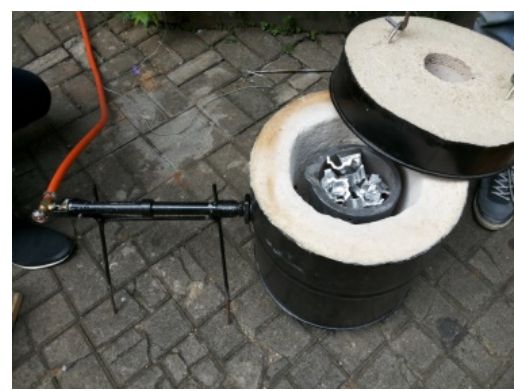

Gambar 4. Proses peleburan bahan baku

\section{d. Pembentukan specimen}

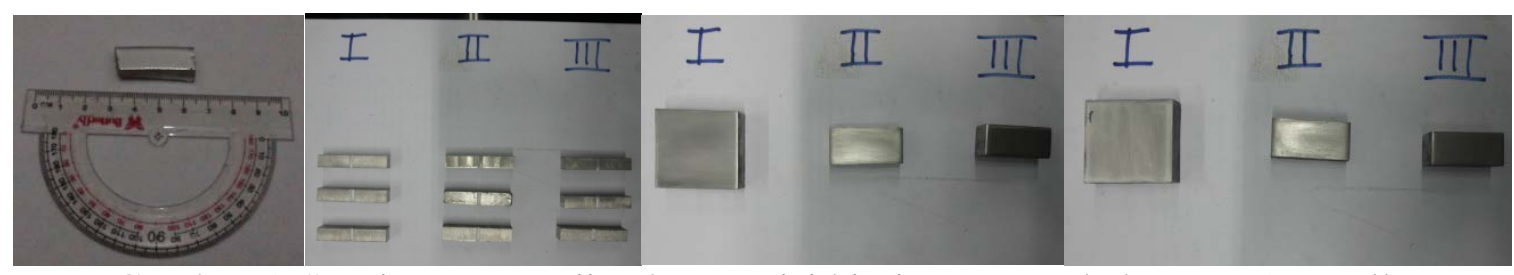

Gambar 5. Spesimen pengujian komposisi kimia, Impact, kekerasan (Brinell), pengamatan struktur mikro. 


\section{e. Pengujian komposisi kimia}

Pengujian ini dilakukan dengan merujuk pada ASTM E1251, dilaksanakan di Laboratorium Uji Departemen Teknik Metalurgi \& Material Universitas Indonesia. Tujuan dilakukannya pengujian ini adalah untuk mengetahui komposisi kimia dari aluminium paduan seri 6063 dan dapat memastikan bahwa bahan baku yang digunakan benar aluminium paduan seri 6063 .

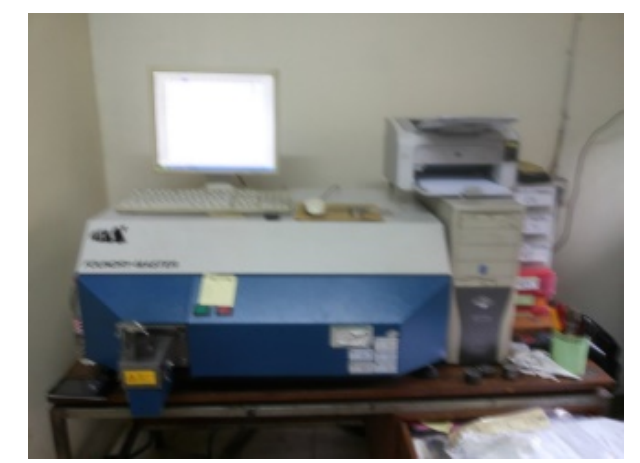

Gambar 6. Pengujian komposisi kimia

\section{f. Pengujian Impact}

Pengujian impact standart ASTM E23 dengan metode charpy yaitu metode dengan pengikiran huruf $\mathrm{V}$ notch dengan kedalaman pada salah satu sisi spesimen yang terletak ditengah-tengah spesimen. Pengujian impact dilakukan di Laboratorium Metalurgi Fisik Universitas Tarumanagara.

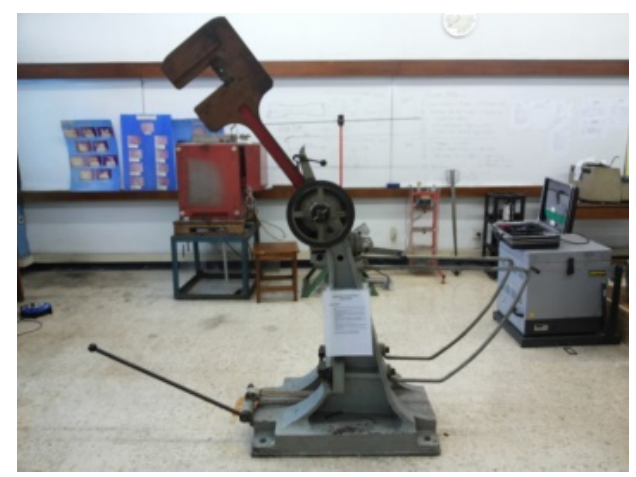

Gambar 7. Pengujian Impact

\section{g. Pengujian kekerasan (Brinell)}

Pengujian brinell standart ASTM E140 dengan mesin AFFRI yaitu mesin brinell portable. Pengujian dilaksanakan di Laboratorium Metalurgi Fisik Universitas Tarumanagara.

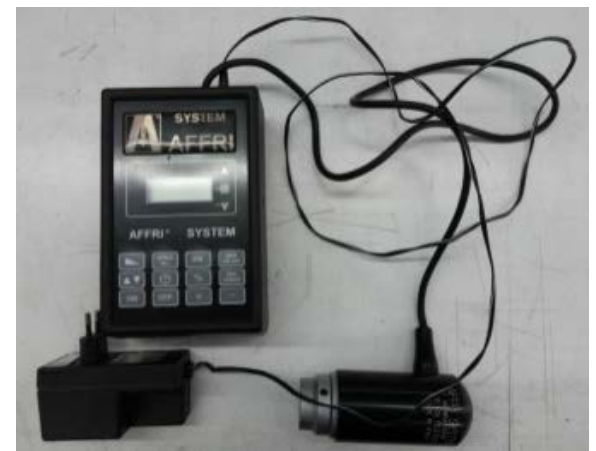

Gambar 8. Pengujian kekerasan (Brinell) 


\section{h. Pengamatan struktur mikro}

Pengamatan struktur mikro standart ASTM E3 dengan mikroskop digital JENCO. Pengujian ini dilakukan di Laboratorium Metrologi Universitas Tarumanagara.

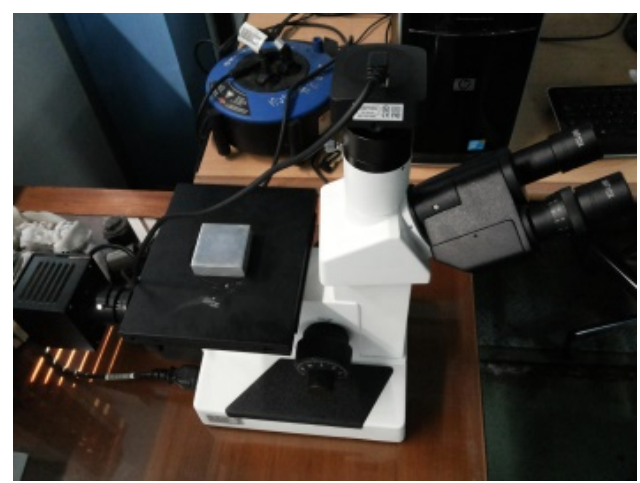

Gambar 9. Pengamatan struktur mikro

\section{HASIL DAN PEMBAHASAN}

a. Pengamatan laju pendinginan

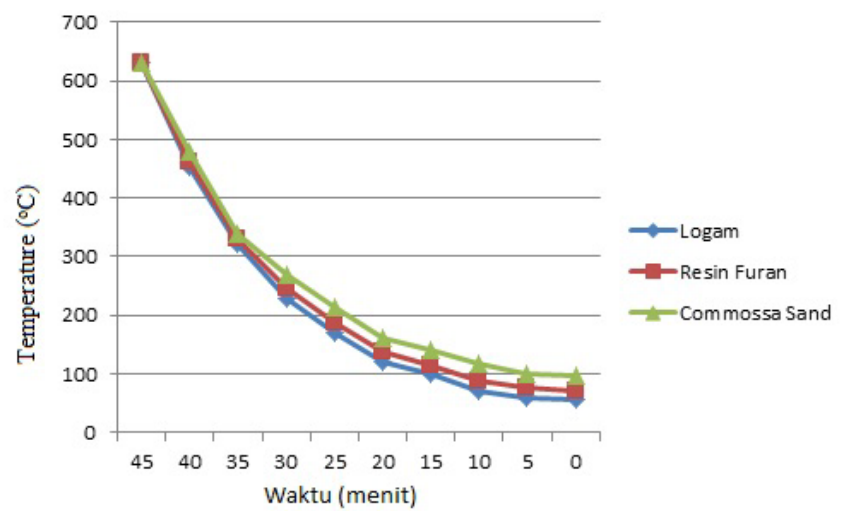

Gambar 10. Grafik pengamatan laju pendinginan

Dari pengamatan laju pendinginan aluminium paduan seri 6063 pada Gambar 10, maka dapat disimpulkan bahwa urutan pendinginan tercepat yaitu cetakan logam, cetakan pasir resin furan, dan cetakan pasir komossa. Logam terbukti sebagai konduktor yang baik melepas kalor.

b. Hasil pengujian komposisi kimia

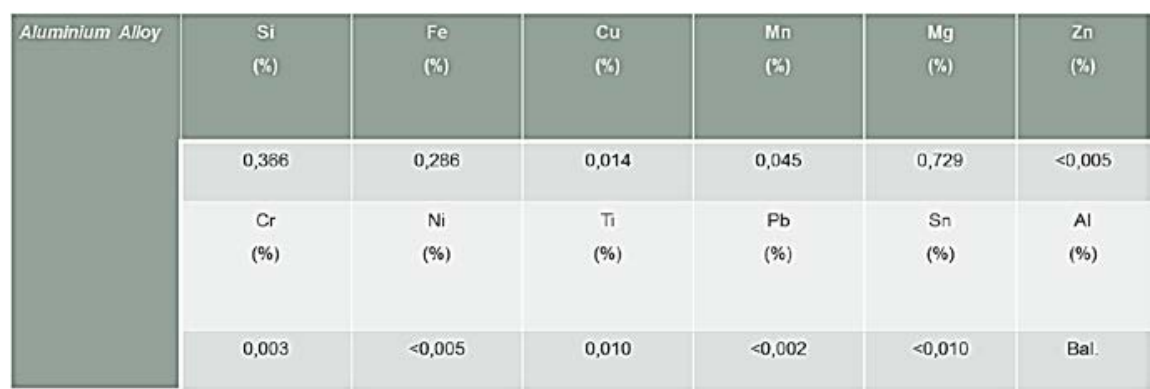

Gambar 11. Tabel pengujian komposisi kimia

Dari hasil penelitian komposisi bahan baku kimia pada Tabel 1, maka dapat disimpulkan bahwa komposisi yang mendominasi aluminium paduan seri 6063 yaitu mangan (Mg) senilai 0,729\% dan silikon (Si) senilai 0,366\% sehingga bahan baku adalah $\mathrm{Al}-\mathrm{Mg}-\mathrm{Si}$. 
c. Hasil pengujian Impact

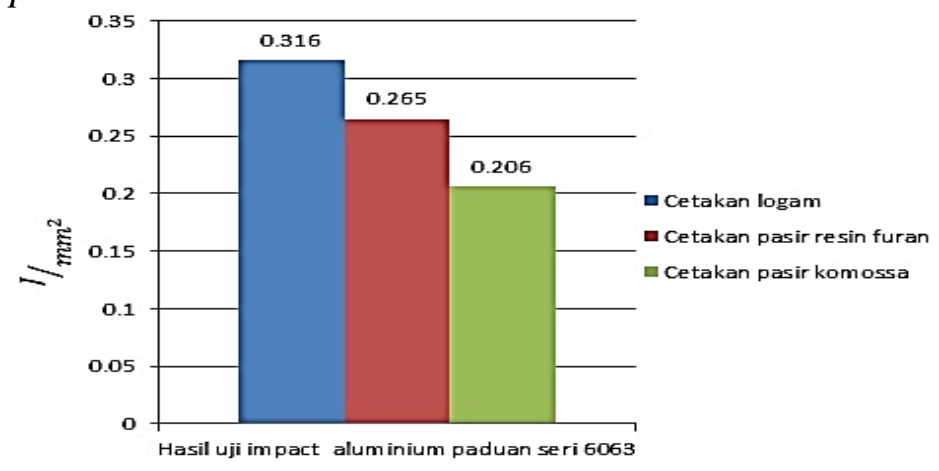

Gambar 12. Bar chart hasil pengujian Impact

Berdasarkan Gambar 12. dapat dilihat bahwa cetakan logam memiliki nilai Impact sebesar $0,316 \mathrm{~J} / \mathrm{mm}^{2}$, cetakan pasir resin furan memiliki nilai impact sebesar $0,265 \mathrm{~J} / \mathrm{mm}^{2}$, dan cetakan pasir komossa memiliki nilai Impact sebesar $0,206 \mathrm{~J} / \mathrm{mm}^{2}$. cetakan logam memiliki nilai Impact 0,051 $\mathrm{J} / \mathrm{mm}^{2}$ yang lebih tinggi dibandingkan dengan cetakan pasir resin furan. Sedangkan cetakan pasir resin furan memiliki nilai Impact 0,059 J/ $\mathrm{mm}^{2}$ lebih tinggi dibandingkan cetakan pasir komossa. Cetakan logam menghasilkan nilai Impact yang paling tinggi, disusul oleh cetakan pasir resin furan dan terakhir cetakan pasir komossa.

d. Hasil pengujian kekerasan (Brinell)

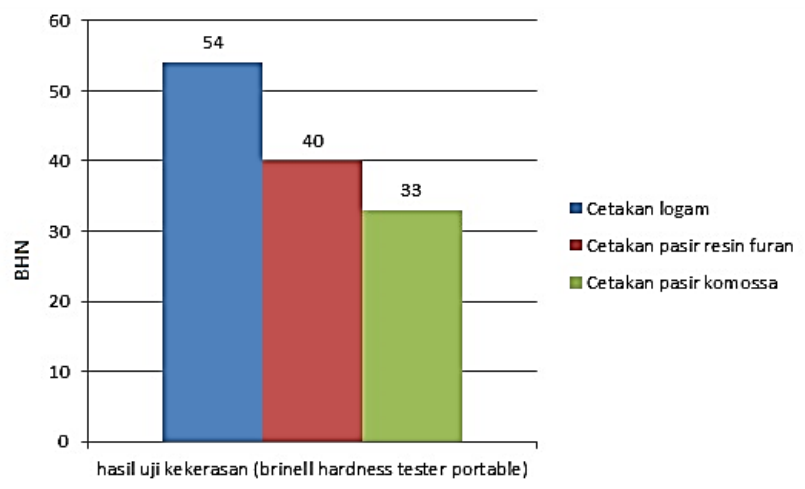

Gambar 13. Bar chart hasil pengujian kekerasan (Brinell)

Dari Gambar 13 terlihat bahwa nilai kekerasan pada cetakan logam lebih tinggi yaitu 54 HRB dibandingkan cetakan pasir resin furan senilai $40 \mathrm{HRB}$ dan cetakan pasir komossa senilai 33 HRB. Jadi, cetakan logam menghasilkan spesimen yang paling keras dibandingkan cetakan lainnya.

e. Hasil pengamatan struktur mikro

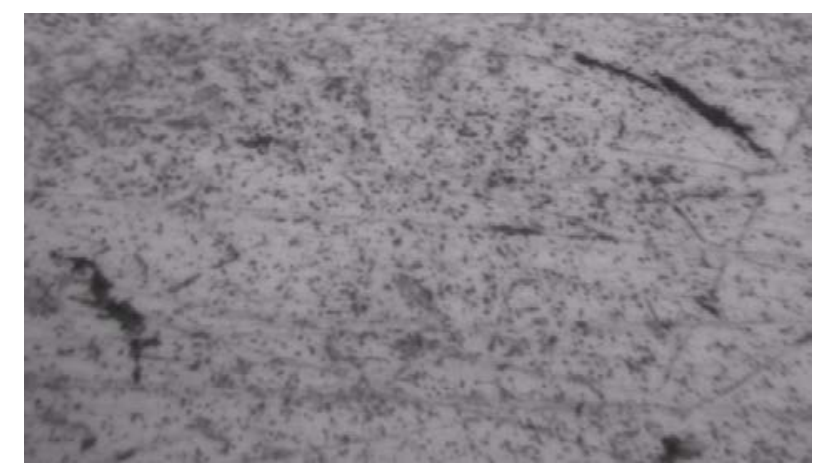

Gambar 14. Hasil pengamatan struktur mikro spesimen cetakan logam 


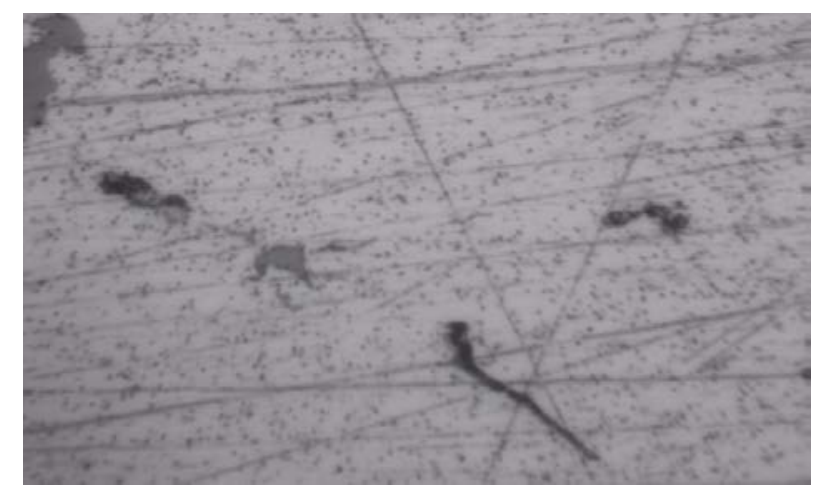

Gambar 15. Hasil pengamatan struktur mikro spesimen cetakan pasir resin furan

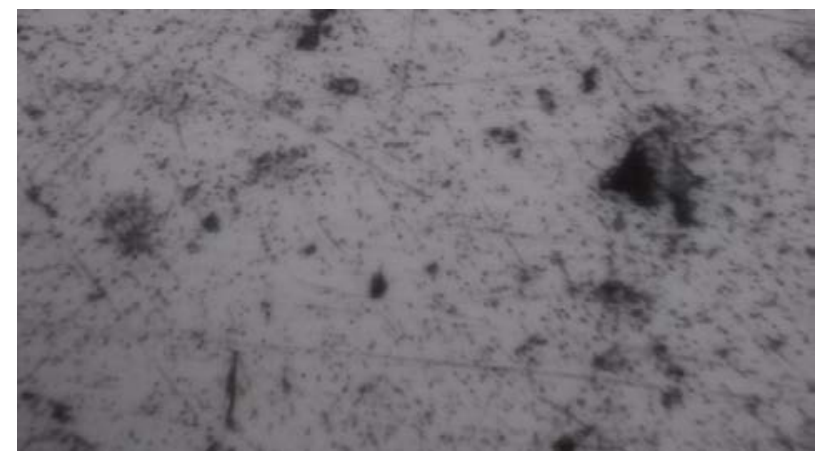

Gambar 16. Hasil pengamatan struktur mikro spesimen cetakan pasir komossa

\section{KESIMPULAN}

Berdasarkan penelitian yang telah dilakukan dapat ditarik kesimpulan, yaitu Laju pendinginan suhu antara cetakan logam, pasir resin furan, dan pasir komossa terlihat berbeda. Laju pendinginan paling cepat ada di cetakan logam dalam 45 menit mencapai $55^{\circ} \mathrm{C}$, cetakan pasir resin furan $71^{\circ} \mathrm{C}$, dan cetakan pasir komossa $95^{\circ} \mathrm{C}$. Untuk Hasil pengujian kekerasan (Brinell) menampilkan cetakan logam memiliki kekerasan yang tinggi dibandingkan cetakan resin furan dan cetakan pasir komossa. 14 BHN selisih kekerasan antara cetakan logam dan cetakan resin furan. Sedangkan selisih antara cetakan resin logam dan cetakan pasir komossa sebesar 7 BHN. Untuk Cetakan logam memiliki nilai Impact 0,051 J/mm $\mathrm{mm}^{2}$ yang lebih tinggi dibandingkan dengan cetakan resin furan. Sedangkan resin furan memiliki nilai impact 0,059 $\mathrm{J} / \mathrm{mm}^{2}$ lebih tinggi dibandingkan cetakan pasir komossa. Untuk pengujian komposisi kimia, bahan baku merupakan aluminium paduan seri 6063 dengan paduan Al-Mg-Si.

\section{DAFTAR PUSTAKA}

[1]. Surdia.Tata, Teknik Pengecoran Logam,Pradnya Paramita,Jakarta, 1997.

[2]. Surjana.Hardi,Teknik Pengecoran Logam,Depdiknas, 2008.

[3]. Harry, Chandler. Hardness Testing, $2^{\text {nd }}$ Edition, ASM Internasional, 1999.

[4]. Kennard Dhammabhakti, Uji Impact, Laporan Praktikum Metalurgi Fisik. Jakarta: Fakultas Teknik, Universitas Tarumanagara. 2014.

[5]. William H. Cubberly. ASM Handbook Metallography and Microstrutures vol 9. Formerly Nint Editition, Metal Hanbook, 1985.

[6]. Fajar, Ismail. Rancang Bangun Uji Impak Charpy, Tugas Akhir. Semarang: Fakultas Teknik, Universitas Diponegoro, 2012.

[7]. Mulyadi shaleh, Irfan, Amd. Pengetahuan Dasar Teknik Mesin.Martapura. 2008.

[8]. Samsudi Raharja, Fuad Abdillah, Yugohindra Wanto, Analisa Pengaruh Pengecoran Ulang Terhadap Sifat Mekanik Paduan Aluminium ADC 12, Fakultas Teknik, Universitas Muhammadiyah Semarang, 2009. 